\title{
4G/5G polymorphism of PAl- 1 gene is associated with multiple organ dysfunction and septic shock in pneumonia induced severe sepsis: prospective, observational, genetic study
}

\author{
Krisztina Madách*+1, István Aladzsity², Ágnes Szilágyi2,3, George Fust², János Gál1, István Pénzes and
}

Zoltán Prohászka2,3

\begin{abstract}
Introduction: Activation of inflammation and coagulation are closely related and mutually interdependent in sepsis. The acute-phase protein, plasminogen activator inhibitor-1 (PAI-1) is a key element in the inhibition of fibrinolysis. Elevated levels of PAI- 1 have been related to worse outcome in pneumonia. We aimed to evaluate the effect of functionally relevant $4 \mathrm{G} / 5 \mathrm{G}$ polymorphism of PAI-1 gene in pneumonia induced sepsis.

Methods: We enrolled 208 Caucasian patients with severe sepsis due to pneumonia admitted to an intensive care unit (ICU). Patients were followed up until ICU discharge or death. Clinical data were collected prospectively and the PAI-1 4G/5G polymorphism was genotyped by polymerase chain reaction-restriction fragment length polymorphism technique. Patients were stratified according to the occurrence of multiple organ dysfunction syndrome, septic shock or death.
\end{abstract}

Results: We found that carriers of the PAI-1 4G/4G and 4G/5G genotypes have a 2.74-fold higher risk for multiple organ dysfunction syndrome (odds ratio [OR] 95\% confidence interval $[\mathrm{Cl}]=1.335-5.604 ; p=0.006$ ) and a 2.57-fold higher risk for septic shock (OR 95\% Cl $=1.180-5.615 ; p=0.018)$ than $5 \mathrm{G} / 5 \mathrm{G}$ carriers. The multivariate logistic regression analysis adjusted for independent predictors, such as age, nosocomial pneumonia and positive microbiological culture also supported that carriers of the $4 \mathrm{G}$ allele have a higher prevalence of multiple organ dysfunction syndrome (adjusted odds ratio $[\mathrm{aOR}]=2.957 ; 95 \% \mathrm{Cl}=1.306-6.698 ; p=0.009)$ and septic shock $(\mathrm{aOR}=2.603 ; 95 \% \mathrm{Cl}=1.137$ 5.959; $p=0.024$ ). However, genotype and allele analyses have not shown any significant difference regarding mortality in models non-adjusted or adjusted for acute physiology and chronic health evaluation (APACHE) II. Patients bearing the $4 \mathrm{G}$ allele had higher disseminated intravascular coagulation (DIC) score at admission ( $p=0.007$ ) than $5 \mathrm{G} / 5 \mathrm{G}$ carriers. Moreover, in $4 \mathrm{G}$ allele carriers the length of ICU stay of non-survivors was longer ( $p=0.091)$, fewer ventilationfree days $(p=0.008)$ and days without septic shock $(p=0.095)$ were observed during the first 28 days.

Conclusions: In Caucasian patients with severe sepsis due to pneumonia carriers of the $4 \mathrm{G}$ allele of PAI- 1 polymorphism have higher risk for multiple organ dysfunction syndrome and septic shock and in agreement they showed more fulminant disease progression based on continuous clinical variables.

\section{Introduction}

Sepsis is a complex clinical syndrome that results from an infection-triggered systemic inflammatory response.

\footnotetext{
* Correspondence: madachk@gmail.com

1 Department of Anesthesiology and Intensive Therapy, Semmelweis

University, Kútvölgyi út 4, Budapest, H-1125, Hungary

† Contributed equally

Full list of author information is available at the end of the article
}

Despite significant advances in supportive care and in research on its pathogenesis, sepsis remains the leading cause of death in critically ill patients [1].

Patients with apparently similar general condition and severity of infection may present profoundly different survival rates. Individual differences in disease manifestation are influenced by the genetic predisposition of the 
patient, as recognized by the PIRO (predisposition, infection, response, organ dysfunction) concept [2]. Single nucleotide polymorphisms (SNPs) in genes involved in the inflammatory response that influence sepsis susceptibility or severity may explain the clinical variability observed during the course of similar infections.

It is already known that activation of inflammation and coagulation are closely related and mutually interdependent in sepsis [3]. The imbalance between fibrin generation and dissolution contributes to disseminated intravascular coagulation and multiple organ dysfunction syndrome (MODS) [4].

The glycoprotein serine protease plasminogen activator inhibitor-1 (PAI-1) is a key element in the inhibition of fibrinolysis. The primary role of PAI-1 in vivo is fast acting inhibition of tissue- and urokinase-type plasminogen activators. PAI-1 is also an acute-phase protein during acute inflammation. Plasma levels of PAI-1 are influenced by genetic, metabolic, endocrine, dietary, and physical activity factors, and they strongly increase in response to inflammation and injury [5-10]. The alveolar compartment is an important site of PAI-1 production and activity. Several studies demonstrated worse outcomes in patients hospitalized due to acute lung injury, acute respiratory distress syndrome and severe pneumonia who had increased levels of PAI-1 in bronchoalveolar lavage fluid and plasma $[11,12]$. In patients with sepsis, the levels of PAI-1 are positively related to poor outcome, increased severity of the disease, and increased levels of various cytokines, acute-phase proteins, and coagulation parameters [13].

The gene coding for PAI-1 has several polymorphic loci among which the most studied is the 4G/5G insertion/ deletion polymorphism (rs1799768) containing either four or five (4G/5G) guanine bases at -675 within the promoter region of the human PAI-1 (SERPINE1) gene [14]. Both alleles of this SNP can bind a transcriptional activator, whereas the $5 \mathrm{G}$ allele binds a repressor protein at an overlapping site. Therefore homozygosity for the $4 \mathrm{G}$ allele renders this negative regulator unable to act, resulting in greater transcription of the PAI-1 gene, while heterozygotes show intermediate phenotype $[4,15]$. The $4 \mathrm{G}$ allele of the $4 \mathrm{G} / 5 \mathrm{G}$ polymorphism has been associated with increased susceptibility to community-acquired pneumonia, and increased mortality in hospitalized patients with severe pneumonia $[16,17]$. In addition, the $4 \mathrm{G}$ allele was reported to affect the risk of developing severe complications and higher mortality in meningococcal sepsis and trauma [18-22]. Based on the above mentioned studies, we hypothesized that the carriers of the 4G allele of PAI-1 polymorphism have higher risk for worse outcome in pneumonia-induced sepsis.

While evaluating the effects of SNPs on individual differences in the manifestation of sepsis, clinical factors, such as the etiology of the infectious process, the virulence of the pathogenic microorganism, undrainable surgical source of sepsis, the time to hospital admission and adequate treatment, the presence of comorbidities, and differences in racial origin and gender distribution, clearly act as confounding agents. Aimed at minimizing these confounding agents - frequently not taken into consideration in previous studies - we evaluated the effect of the 4G/5G polymorphism of the PAI-1 gene on the occurrence of organ dysfunction, severity of the disease and mortality in a relatively homogenous cohort of patients: only Caucasian subjects with severe sepsis due to pneumonia were included in the study.

\section{Materials and methods Patients and definitions}

From an original cohort of 301 critically ill patients diagnosed with sepsis consecutively admitted to the Department of Anesthesiology and Intensive Therapy of Semmelweis University, 208 patients met the criteria of severe sepsis due to pneumonia and were enrolled in the study within 24 hours of admission to the ICU. The study enrolment was carried out between June 2004 and June 2007. Exclusion criteria were: primary site of infection other than lungs, undrainable surgical source of sepsis, malignancy and final stage of chronic disease, chronic treatment with steroids or immunosuppressive drugs, AIDS and pregnancy. Patients were treated according to the Surviving Sepsis Campaign guidelines for the management of severe sepsis and septic shock [23]. Patients received empiric broad-spectrum antibiotic therapy according to the expected susceptibility of the probable pathogen. After receiving positive results (lower respiratory tract or blood culture) we de-escalated antibiotic therapy according to susceptibility of the pathogens. All patients were followed up during their hospital stay until they were discharged from the ICU or died. MODS, septic shock and death of any cause were registered as endpoints of the study. Continuous variables characterising severity of illness progression such as ICU length of stay, invasive ventilation-free days and days without septic shock during the first 28 days were also evaluated.

The diagnosis of pneumonia was made on the basis of appearance of new infiltrate on the chest $x$-ray in the presence of cough or fever. All patients met the criteria of the British Thoracic Society for severe pneumonia [24]. MODS has been defined as "the presence of altered organ function in an acutely ill patient such that homeostasis cannot be maintained without intervention" [25]. Clinically, MODS was considered as a sequential or concomitant occurrence of a significant derangement of function in two or more organ systems of the body, against a background of critical illness. Severe sepsis was defined as acute organ dysfunction secondary to infection, and sep- 
tic shock defined as severe sepsis resulting in hypotension despite adequate fluid resuscitation according to the 2001 SCCM/ESICM/ACCP/ATS/SIS International Sepsis Definitions Conference [26]. Sepsis-induced hypotension was defined as systolic blood pressure of less than 90 $\mathrm{mmHg}$, mean arterial pressure of less than $60 \mathrm{mmHg}$ or a systolic blood pressure decrease of more than $40 \mathrm{mmHg}$ in the absence of other cause of hypotension. Disseminated intravascular coagulation (DIC) score was calculated at admission according to the International Society on Thrombosis and Haemostasis [27].

Written informed consent was obtained from patients or their relatives, and the study was approved by the local ethics committee.

Genomic DNA was extracted from white blood cells using the method described by Miller and colleagues [28]. The PAI-1 -675 locus was amplified using the forward 5'CACAGAGA GAGTCTGGCCACGT-3' and the reverse 5'-CCAACAGAGGACTCTTGGTCT-3' primers. The amplified DNA was incubated with $B s l$ restriction enzyme and the cleaved fragments were analyzed by electrophoresis in a 2\% gel with ethidium bromide [29].

Data were collected in MS Excel 2003 (Microsoft, Redmond, WA, USA) and were analyzed with SPSS 13.0 for Windows (SPSS, Chicago, IL, USA) software. Categorical variables were reported as absolute numbers and percentages, and continuous variables as medians and interquartile ranges. Categorical data were compared using a Pearson Chi-squared test; continuous data were compared with categorical data using nonparametric MannWhitney $U$ and Kruskal-Wallis tests. All reported $p$ values were two-tailed and $p<0.05$ was considered to be significant. Hardy-Weinberg equilibrium analysis was performed by comparing the detected genotype distribution with the theoretical distribution estimated on the basis of the allele frequencies.

Multiple logistic regression analysis was used to evaluate independent predictors $(p<0.05)$ for the three endpoints. Hazard risk of in ICU mortality associated with genotypes and other independent variables was estimated using a Cox proportional hazards regression analysis.

Post-hoc power analysis was performed by Statistica software (Tulsa, OK, USA) for chi-squared test. With our sample sizes (the numbers of patients in the subgroups with MODS, shock and non-survivors were 121, 89 and 78 , respectively) the minimal genotype frequency difference to be detected with a power of 0.8 , were $0.145,0.135$ and 0.132 , respectively.

\section{Results}

\section{Patient characteristics}

Of the 208 enrolled patients one was excluded due to insufficient DNA quality for genotype determination. The median age of the 207 septic patients was 65 (53 to
75) years and their gender distribution was $50.2 \%$ males and $49.8 \%$ females.

All patients had at least one organ dysfunction (respiratory insufficiency) and 121 (58.5\%) had MODS. Eighty nine $(43 \%)$ subjects met the criteria for septic shock and 78 (37.7\%) patients died during the ICU stay. The cause of deaths was cardiovascular collapse due to MODS. One hundred and sixty-three $(78.7 \%)$ patients required invasive and $44(21.3 \%)$ required non-invasive ventilation during the ICU stay. Pathogen microorganism could not be confirmed in $86(41.5 \%)$ cases.

Analyzing the differences among cohorts stratified by the three end-points, we found that the median age was significantly higher in patient with worse outcomes (MODS, septic shock and non-surviving patients; Table 1). There was a tendency toward lower mortality in women than in men $(p=0.051)$. The incidence of comorbid conditions did not differ in the three end-points, except for pulmonary hospitalization in the two years preceding current ICU stay, which was, interestingly, less frequent in the septic shock cohort than in severe sepsis and nosocomial infection, which was significantly more prevalent in patients with MODS and septic shock as compared with the group of non-MODS and severe sepsis, respectively. As expected, patients with worse outcomes had higher Acute Physiology and Chronic Health Evaluation II (APACHE II) and DIC scores at admission. Occurrence of MODS $(p<0.001)$ and septic shock $(p=$ 0.011 ) was significantly more prevalent in patients with positive culture and targeted antibiotic treatment than in unconfirmed cases with empiric treatment.

\section{Genotype distribution}

Distribution of the genotypes of PAI-1 SNP is shown in Table 2. In the studied population, the genotype frequencies were: $4 \mathrm{G} / 4 \mathrm{G}=30.4 \%(\mathrm{n}=63) ; 4 \mathrm{G} / 5 \mathrm{G}=50.7 \%(\mathrm{n}=$ $105)$; and $5 \mathrm{G} / 5 \mathrm{G}=18.8 \%(\mathrm{n}=39)$. Genotype frequencies were in Hardy-Weinberg equilibrium ( $p=0.92)$. The calculated allele frequency was 0.56 for $4 \mathrm{G}$ and 0.44 for $5 \mathrm{G}$.

\section{Clinical associations of PAI-1 4G/5G polymorphism}

The incidence of MODS, septic shock and non-survival were similar and higher in carriers of 4G/4G and 4G/5G genotypes than in patients with 5G/5G genotype. Therefore, these two genotypes were combined in further analyses (Table 2.).

Genotype distribution and allele frequencies of the PAI-1 4G/5G polymorphism stratified by MODS, sepsis severity and ICU mortality are shown in Table 3. The 4G/ $4 \mathrm{G}$ and 4G/5G genotypes were significantly more frequent in MODS and in septic shock compared with nonMODS and severe sepsis, respectively. Consequently the risk of MODS was 2.74-fold (odds ratio $(\mathrm{OR})=2.74$ 95\% confidence interval $(\mathrm{CI})=1.335$ to $5.604 ; p=0.006)$ and 
Table 1: Summary of patient characteristics stratified by multiple organ dysfunction, sepsis severity and mortality

\begin{tabular}{|c|c|c|c|c|c|c|}
\hline \multirow[b]{2}{*}{$\begin{array}{l}\text { Patient characteristics } \\
\text { Median (quartiles) or \% }\end{array}$} & \multicolumn{2}{|c|}{ Multiple organ dysfunction } & \multicolumn{2}{|c|}{ Sepsis severity } & \multicolumn{2}{|c|}{ ICU mortality } \\
\hline & $\begin{array}{l}\text { Non-MODS } \\
(n=86)\end{array}$ & $\begin{array}{l}\text { MODS } \\
(n=121)\end{array}$ & $\begin{array}{l}\text { Severe sepsis } \\
(n=118)\end{array}$ & $\begin{array}{l}\text { Septic shock } \\
(n=89)\end{array}$ & $\begin{array}{l}\text { Survivors } \\
(n=129)\end{array}$ & $\begin{array}{l}\text { Non-survivors } \\
(\mathrm{n}=78)\end{array}$ \\
\hline \multicolumn{7}{|l|}{ Demographics } \\
\hline Age (years) & $58.5(48-68)^{*}$ & $70(59-77)^{*}$ & $61(51-71)^{*}$ & $72(59-77)^{*}$ & $61(50-70)^{*}$ & $72.5(61-79)^{*}$ \\
\hline Male sex, $\%$ & 45.3 & 53.7 & 46.6 & 55.1 & 45.0 & 59.0 \\
\hline \multicolumn{7}{|l|}{ Previous or preexisting conditions } \\
\hline Days of complaint before admission, (days) & $4(2-7)$ & $4(1-10)$ & $4(2-8)$ & $4(1-9)$ & $4(1-7.5)$ & $4(2-10)$ \\
\hline Pulmonary hospitalisation in the past two years, $\%$ & 27.9 & 24.8 & $31.4^{*}$ & $19.1^{*}$ & 27.9 & 23.1 \\
\hline Cachexia, \% & 12.8 & 17.4 & 12.7 & 19.1 & 14.0 & 17.9 \\
\hline Nosocomial pneumonia, $\%$ & $25.6^{*}$ & $44.6^{*}$ & $30.5^{*}$ & $44.9^{*}$ & 32.6 & 43.6 \\
\hline Ischemic heart disease, \% & 33.7 & 43.8 & 37.3 & 42.7 & 36.4 & 44.9 \\
\hline COPD, \% & 43.0 & 33.1 & 42.4 & 30.3 & 39.5 & 33.3 \\
\hline Hypertension, \% & 55.8 & 62.8 & 59.3 & 60.7 & 58.1 & 62.8 \\
\hline Diabetes mellitus, \% & 24.4 & 27.3 & 26.3 & 25.8 & 24.0 & 29.5 \\
\hline Active and ever (>15 years) smoking, $\%$ & 46.5 & 42.1 & 46.6 & 40.4 & 46.5 & 39.7 \\
\hline Alcohol consumption > 1 glass/day, $\%$ & 9.3 & 13.2 & 9.3 & 14.6 & 10.9 & 12.8 \\
\hline \multicolumn{7}{|l|}{ ICU conditions } \\
\hline 28 days mortality, $\%$ & $0.0^{*}$ & $62.8^{*}$ & $9.3^{*}$ & $73.0^{*}$ & $0.0^{*}$ & $97.4^{*}$ \\
\hline ICU mortality, \% & $0.0^{*}$ & $64.5^{*}$ & $9.3^{*}$ & $75.3^{*}$ & - & - \\
\hline APACHE II score at admission & $18(14-22)^{*}$ & $24(18.5-30.5)^{*}$ & $19(15-23)^{*}$ & $25(20-31)^{*}$ & $19(15-23)^{*}$ & $25(22-31)^{*}$ \\
\hline DIC score at admission & $0(0-2)^{*}$ & $3(0-4)^{*}$ & $0(0-2)^{*}$ & $3(2-5)^{*}$ & $0(0-2)^{*}$ & $3(2-4)^{*}$ \\
\hline ICU length of stay, (days) & $8(5-12)$ & $8(5-16.5)$ & $8(5-12)$ & $8(4.5-16.5)$ & $9(5-15)$ & $8(4-12)$ \\
\hline Horowitz quotient of invasively ventilated patients, $\left(\mathrm{PaO}_{2} / \mathrm{FiO}_{2}\right)$ & $269.0(161.3-342.3)^{*}$ & $179.6(126.2-232.4)^{*}$ & $222.0(149.9-335.4)^{*}$ & $175.2(119.7-229.7)^{*}$ & $197.5(139.1-305.5)$ & $188.3(124.2-241.6)$ \\
\hline ARDS, \% & $7.0^{*}$ & $24.0^{*}$ & $8.5^{*}$ & $28.1^{*}$ & $11.6^{*}$ & $25.6^{*}$ \\
\hline Invasive ventilation, \% & $52.3^{*}$ & $97.5^{*}$ & $62.7^{*}$ & $100.0^{*}$ & $65.9^{*}$ & $100.0^{*}$ \\
\hline Length of invasive ventilation, (days) & $5(3.5-7.5)^{*}$ & $8(4-13.3)^{*}$ & $5.5(4-10.3)$ & $7(4-14)$ & $6(4-13)$ & $7(4-12)$ \\
\hline Tracheotomy, \% & $5.8^{*}$ & $14.9^{*}$ & 10.2 & 12.4 & 10.9 & 11.5 \\
\hline Hemodialysis, \% & $7.0^{*}$ & $17.4^{*}$ & 9.3 & 18.0 & $9.3^{*}$ & $19.2^{*}$ \\
\hline
\end{tabular}


Table 1: Summary of patient characteristics stratified by multiple organ dysfunction, sepsis severity and mortality (Continued)

\begin{tabular}{|c|c|c|c|c|c|c|}
\hline \multicolumn{7}{|l|}{ Infection types } \\
\hline Unconfirmed, \% & $55.8^{*}$ & $31.4^{*}$ & $49.2^{*}$ & $31.5^{*}$ & 45.0 & 35.9 \\
\hline \multicolumn{7}{|l|}{ Confirmed, \% } \\
\hline Gram positive & 10.5 & 19.3 & 11.7 & 21.3 & 15.5 & 18.0 \\
\hline Gram negative & 52.6 & 57.8 & 60.0 & 52.5 & 52.1 & 62.0 \\
\hline Atypical pneumonia (Chlamydia, Mycoplasma, Legionella) & 23.7 & 14.5 & 18.3 & 16.4 & 21.1 & 12.0 \\
\hline Mixed & 13.2 & 8.4 & 10.0 & 9.8 & 11.3 & 8.0 \\
\hline
\end{tabular}

*Statistical significance $(P<0.05)$ of comparing the groups of non-MODS vs. MODS, severe sepsis vs. septic shock and survivors vs. non-survivors by Mann-Whitney or Pearson Chi-square tests

APACHE II, acute physiology and chronic health evaluation II; ARDS, acute respiratory distress syndrome; COPD, chronic obstructive pulmonary disease; DIC, disseminated intravascular coagulation;

$\mathrm{FiO}_{2}$, fraction of inspired oxygen; $\mathrm{MODS}$, multiple organ dysfunction syndrome; $\mathrm{PaO}_{2}$, partial pressure of arterial oxygen. 
Table 2: The incidence of MODS, septic shock and non-survival in carriers of the different PAI-1 4G/5G genotypes

\begin{tabular}{lllll}
\hline Genotype & n & MODS (\%) & Septic shock (\%) & Non-survivors (\%) \\
\hline $4 G / 4 G$ & 63 & $39(61.9 \%)$ & $32(50.8 \%)$ & $27(42.9 \%)$ \\
$4 G / 5 G$ & 105 & $67(63.8 \%)$ & $47(44.8 \%)$ & $41(39.0 \%)$ \\
$5 G / 5 G$ & 39 & $15(38.5 \%)$ & $10(25.6 \%)$ & $10(25.6 \%)$ \\
\hline
\end{tabular}

MODS, multiple organ dysfunction syndrome; PAI-1, plasminogen activator inhibitor 1.

the risk of septic shock was 2.57 -fold $(\mathrm{OR}=2.57) 95 \% \mathrm{CI}$ $=1.180$ to $5.615 ; p=0.018$ ) higher in carriers of the $P A I-1$ 4G/4G and 4G/5G genotypes than in individuals bearing the 5G/5G genotype. Accordingly, the frequency of $P A I-1$ $4 \mathrm{G}$ allele in the group of MODS (OR $=1.495 ; 95 \% \mathrm{CI}=$ 1.008 to $2.217 ; p=0.045)$ and septic shock $(\mathrm{OR}=1.601$; $95 \% \mathrm{CI}=1.077$ to $2.381 ; p=0.019)$ was significantly different from that of non-MODS and severe sepsis, respectively.

Comparing the genotype distribution between surviving and non-surviving patients, there was a tendency towards higher frequency of the 4G/4G and 4G/5G genotypes $(p=0.085)$ in non-survivors. However, allele frequencies of the PAI-1 4G/5G polymorphism were not different in the same subgroups.

Analyzing the DIC score at admission among carriers of different PAI-1 genotypes, we found that patients bearing the 4G allele had significantly higher DIC scores at the time of admission than 5G/5G homozygotes (2 (0 to $3)$ vs. 0 (0 to 2$), p<0.007)$. We also evaluated the association of PAI-1 polymorphism with ICU length of stay, invasive ventilation-free days and days without septic shock during the first 28 days of ICU stay. The length of ICU stay did not differ between carriers and non-carriers of the $4 \mathrm{G}$ allele $(p=0.858)$. However, in non-survivors the median ICU length of stay was more than two days lower in patients with the $4 \mathrm{G}$ allele than in $5 \mathrm{G} / 5 \mathrm{G}$ patients $(6$ ( 4 to 11 ) vs. 8.5 (6 to 18$), p=0.091$ ). Carriers of the $4 \mathrm{G}$ allele had significantly less invasive ventilation free-days during the first 28 days than patients with the $5 \mathrm{G} / 5 \mathrm{G}$ genotype (0 (0 to 0$)$ vs. 0 (0 to 6$), p=0.008$ ). The median of days without septic shock during the first 28 days was lower in patients bearing the 4G/4G and 4G/5G genotypes than in carriers of the $5 \mathrm{G} / 5 \mathrm{G}$ genotype ( 4 ( 0 to 9 ) vs. 6 (5 to 9 ), $p$ $=0.095)$.

\section{Multivariate analysis of factors associated with endpoints}

By multivariate logistic regression analysis, three factors were independently associated with MODS and sepsis severity: age, incidence of nosocomial pneumonia and positive microbiological culture. Therefore, these three parameters were introduced simultaneously as adjusting variables in logistic regression models of MODS and severity. The adjusted model indicated an independent association of PAI-I 4G/5G and 4G/4G genotypes with MODS and septic shock (Table 4).

A possible association between baseline variables and ICU mortality was studied by multivariate regression analysis as well. Because of multicolinearity, only the APACHE II score turned out to be independent predictor

Table 3: Distribution of PAI-1 4G/5G genotypes and alleles as stratified according to multiple organ dysfunction, sepsis severity and mortality

\begin{tabular}{|c|c|c|c|c|c|c|c|c|c|}
\hline & \multicolumn{3}{|c|}{ Multiple organ dysfunction } & \multicolumn{3}{|c|}{ Sepsis severity } & \multicolumn{3}{|c|}{ ICU mortality } \\
\hline & $\begin{array}{l}\text { Non-MODS } \\
(n=86)\end{array}$ & $\begin{array}{l}\text { MODS } \\
(n=121)\end{array}$ & $p$ value* & $\begin{array}{l}\text { Severe } \\
\text { sepsis } \\
(n=118)\end{array}$ & $\begin{array}{l}\text { Septic } \\
\text { shock } \\
(n=89)\end{array}$ & pvalue* & $\begin{array}{l}\text { Survivors } \\
(n=129)\end{array}$ & $\begin{array}{l}\text { Non-survivors } \\
(n=78)\end{array}$ & $p$ value* \\
\hline \multicolumn{10}{|l|}{ Genotype } \\
\hline $4 \mathrm{G} / 4 \mathrm{G}$ and $4 \mathrm{G} / 5 \mathrm{G}$ & $62(72.1 \%)$ & $106(87.6 \%)$ & & $89(75.4 \%)$ & $79(88.8 \%)$ & & $100(77.5 \%)$ & $68(87.2 \%)$ & \\
\hline $5 \mathrm{G} / 5 \mathrm{G}$ & $24(27.9 \%)$ & $15(12.4 \%)$ & 0.005 & $29(24.6 \%)$ & $10(11.2 \%)$ & 0.015 & $29(22.5 \%)$ & $10(12.8 \%)$ & 0.085 \\
\hline \multicolumn{10}{|l|}{ Allele } \\
\hline $4 G$ & $86(50.0 \%)$ & $145(59.9 \%)$ & & $120(50.8 \%)$ & $111(62.4 \%)$ & & $136(52.7 \%)$ & $95(60.9 \%)$ & \\
\hline $5 G$ & $86(50.0 \%)$ & 97 (40.1\%) & 0.045 & $116(49.2 \%)$ & 67 (37.6\%) & 0.019 & $122(47.3 \%)$ & 61 (39.1\%) & 0.104 \\
\hline
\end{tabular}

*Pearson Chi-square tests

MODS, multiple organ dysfunction syndrome; PAI-1, plasminogen activator inhibitor 1. 
for ICU death. Therefore, this single parameter was introduced into the model. A tendency for increased risk of death was observed for the carriers of $4 \mathrm{G} / 4 \mathrm{G}$ and $4 \mathrm{G} / 5 \mathrm{G}$ genotypes after adjustment (Table 4). This result was confirmed by using Cox regression analysis adjusted for APACHE II score as a covariate (4G/4G and 4G/5G hazard ratio $=1.866 ; 95 \% \mathrm{CI}=0.897$ to $3.882 ; p=0.095)$.

\section{Discussion}

This study is unique in evaluating the effect of PAI-1 4G/ $5 \mathrm{G}$ polymorphism on MODS, sepsis severity and mortality in a relatively homogeneous cohort of patients of the same ethnicity. Moreover, this study is the first report, to our knowledge, that shows genetic association between the $4 \mathrm{G}$ allele of $4 \mathrm{G} / 5 \mathrm{G}$ polymorphism and the occurrence of MODS and septic shock in pneumonia sepsis.

Comparing the allele frequencies of PAI-1 4G/5G polymorphism of the studied population and that of other collections of Caucasian healthy individuals (frequency of $4 \mathrm{G}$ allele varied in between 0.51 and 0.55 ), no difference could be found $[18,30]$.

Based on the distribution of PAI-1 genotypes in the three endpoints of the study, the $4 \mathrm{G} / 4 \mathrm{G}$ and $4 \mathrm{G} / 5 \mathrm{G}$ groups were combined for further analyses. Previous studies used both the comparison of $5 \mathrm{G}$ carriers versus 4G/4G and 4G carriers versus 5G/5G patients [16,31]. According to the intermediate PAI-1 level in heterozygotes, both classifications could be correct [32]

Our results showed that the risk of MODS after pneumonia sepsis was almost three times higher in carriers of the PAI-1 4G/5G and 4G/4G genotypes than in patients bearing the 5G/5G genotype. The multivariate logistic regression analysis adjusted for gender, age and nosocomial pneumonia also supported the hypothesis that the PAI-1 4G/5G polymorphism was an independent predictor of MODS. A definite explanation for the development of MODS has not yet been found; accordingly several hypotheses exist for its pathogenesis. One of them is the microvascular failure hypothesis suggesting that microvascular thrombosis may be responsible for clinical MODS [33]. Plasma PAI-1 plays an important role in microvascular fibrin depositing in septic cases and therefore may contribute to MODS and decreased survival in such patients [34]. Moreover, Menges and colleagues showed an association between the PAI-1 4G allele and MODS in severely injured patients [21] while GarciaSegarra and colleagues found the same effect in a cohort of septic shock patients studying sepsis of mixed origin [20].

In addition, both adjusted and non-adjusted models supported a higher risk for septic shock in carriers of the PAI-1 4G allele. These findings were in agreement with the study by Westendorp and colleagues who found that patients with meningococcal disease whose relatives were carriers of the 4G/4G genotype had a six-fold higher risk of developing septic shock compared with all other genotypes [22]. On the other hand, Garcia-Segarra and colleagues and Jessen and colleagues have reported that the 4G allele of the PAI-1 gene was not associated with septic shock in patients with mixed type of sepsis and Gramnegative sepsis [20,35].

Finally, we analyzed the effect of PAI-1 4G/5G polymorphism on mortality. A tendency for a higher rate of non-survival in 4G/4G and 4G/5G carriers was observed with and without adjusting for the confounding variables. Previous studies have yielded positive findings on the impact of the 4G/5G polymorphism on mortality in subjects with sepsis due to meningococcus meningitis, trauma and burn injury $[18,20,21,29,30,36]$. However, others were unable to demonstrate an association between this polymorphism and mortality in patients

Table 4: Multivariate logistic regression analysis of MODS, septic shock and ICU mortality

\begin{tabular}{|c|c|c|c|c|c|c|}
\hline & MODS & & Septic shock & & ICU mortality & \\
\hline & $\begin{array}{l}\text { Odds ratio } \\
\text { (95\% confidence } \\
\text { interval) }\end{array}$ & $p$ value & $\begin{array}{l}\text { Odds ratio } \\
\text { (95\% confidence } \\
\text { interval) }\end{array}$ & $p$ value & $\begin{array}{l}\text { Odds ratio } \\
\text { ( } 95 \% \text { confidence } \\
\text { interval) }\end{array}$ & $p$ value \\
\hline Age, years & $1.048(1.027-1.069)$ & $<0.001$ & $1.032(1.013-1.052)$ & 0.001 & - & - \\
\hline Nosocomial infection & $3.029(1.503-6.102)$ & 0.002 & $2.047(1.104-3.797)$ & 0.023 & - & - \\
\hline Positive microbiological culture & $3.642(1.876-7.069)$ & $<0.001$ & $2.365(1.275-4.386)$ & 0.006 & - & - \\
\hline APACHE II & - & - & - & - & $1.158(1.101-1.217)$ & $<0.001$ \\
\hline \multicolumn{7}{|l|}{ PAl-1 } \\
\hline $5 G / 5 G$ & reference group & & reference group & & reference group & \\
\hline 4G/5G and 4G/4G & $2.957(1.306-6.698)$ & 0.009 & $2.603(1.137-5.959)$ & 0.024 & $1.998(0.879-4.540)$ & 0.098 \\
\hline
\end{tabular}

APACHE II, acute physiology and chronic health evaluation II; MODS, multiple organ dysfunction syndrome. 
with meningococcal sepsis [22] and Gram-negative sepsis [35].

We also analyzed the correlation between PAI-1 genotypes and DIC score and found that carriers of the $4 \mathrm{G}$ allele had higher scores at admission than patients with the $5 \mathrm{G} / 5 \mathrm{G}$ genotype verifying that this polymorphism may influence outcome of sepsis through the disturbance of coagulation. This result was in agreement with the study by Binder and colleagues who found correlation between the PAI-1 4G/5G genotypes and the development of DIC in patients with meningococcal infection [19].

Continuous variables characterising severity of illness progression such as ICU length of stay, invasive ventilation-free days, and days without septic shock during the first 28 days were also evaluated according to genotypes. In the case of ICU length of stay in non-survivors and of the two other variables, $4 \mathrm{G}$ allele carriers showed more fulminant disease progression than 5G/5G homozygotes.

The present study has a number of strengths. The prospective design helps to reduce the phenotype misclassification. We could minimize potential bias by the restriction of inclusion criteria to patients with severe sepsis due to pneumonia, with similar complaint duration until hospital admission, and with no drainable surgical source of sepsis. The homogenous racial cohort limited the confounding genetic factors caused by ethnic heterogeneity. Moreover, we have evaluated the impact of a genetic variant on MODS, sepsis severity and mortality in multivariate regression models in order to avoid the influence of independent predictors.

In spite of the above-mentioned strengths of our study, we declare some limitations. First, a larger study size would probably provide an even stronger statistical power, therefore further studies with increased numbers of patients are required to validate our findings. Second, in this work we tested only one polymorphism of the PAI1 gene and the studied population consisted of relatively elderly subjects. The observed association with the 4G/ $5 \mathrm{G}$ polymorphism may be due to its linkage disequilibrium with other functional polymorphisms in the PAI-1 gene. In contrast, Kathiresan and colleagues identified 2 genetic variants from 18 SNPs of the PAI-1 gene, rs2227631 and the 4G/5G polymorphism, which were in tight linkage disequilibrium with each other and strongly associated with plasma PAI-1 level [37]. We have chosen the 4G/5G insertion/deletion polymorphism for analysis because it is a well-characterized variation of the PAI-1 gene that has been studied both in normal individuals and in different diseases. Third, we could not provide data on PAI-1 serum levels and the DIC score was only available at the time of admission. Follow up of these parameters may give further details on the role of PAI-1 and coagulation in disease progression of pneumoniainduced sepsis.

\section{Conclusions}

In summary, our results indicate that among patients hospitalized with severe sepsis due to pneumonia, carriers of the PAI-1 4G/4G and 4G/5G genotypes have higher risk for MODS and septic shock. This observation supports previous studies reporting that the activation of coagulation and the inhibition of fibrinolysis are important in the pathogenesis of sepsis and support the notion that particular genetic factors may predispose to worse outcome in severe sepsis. Identifying these genetic factors might, in the future, help to choose the appropriate therapy for patients at different risk.

\section{Key messages}

- Carriers of the 4G allele of PAI-1 polymorphism have higher risk for MODS and septic shock in Caucasian patients with severe sepsis due to pneumonia according to both adjusted and non-adjusted analyses.

- Disease progression is more fulminant in $4 \mathrm{G}$ allele carriers as indicated by the association of PAI-1 genotypes with continuous clinical variables such as ICU length of stay in non-survivors, invasive ventilationfree days, and days without septic shock during the first 28 days.

\section{Abbreviations}

APACHE II: acute physiology and chronic health evaluation II; Cl: confidence interval; DIC: disseminated intravascular coagulation; MODS: multiple organ dysfunction syndrome; OR: odds ratios; PAl-1: plasminogen activator inhibitor 1; SNP: single nucleotide polymorphism.

Competing interests

The authors declare that they have no competing interests.

\section{Authors' contributions}

MK and Al were the main researcher for this study and co-contributed to write this manuscript. GJ and PI were involved in the collection of blood samples and clinical data. SzA helped in the technical work. FG and PZ contributed to the experimental design. All authors read, approved and contributed to the final manuscript.

\section{Acknowledgements}

The present study was supported by the National Research Found (OTKA NF 72689)

\section{Author Details}

1 Department of Anesthesiology and Intensive Therapy, Semmelweis University, Kútvölgyi út 4, Budapest, H-1125, Hungary, 23rd Department of Internal Medicine, Research Laboratory, Semmelweis University, Kútvölgyi út 4, Budapest, H-1125, Hungary and ${ }^{3}$ Research Group of Inflammation Biology and Immunogenomics, Semmelweis University and Hungarian Academy of Sciences, Nagyvárad tér 4, Budapest H-1089, Hungary

Received: 20 December 2009 Revised: 23 February 2010 Accepted: 29 April 2010 Published: 29 April 2010

\section{References}

1. Dombrovskiy VY, Martin AA, Sunderram J, Paz HL: Rapid increase in hospitalization and mortality rates for severe sepsis in the United States: a trend analysis from 1993 to 2003. Crit Care Med 2007, 35:1244-1250 
2. Angus DC, Burgner D, Wunderink R, Mira JP, Gerlach H, Wiedermann CJ, Vincent JL: The PIRO concept: P is for predisposition. Crit Care 2003, 7:248-251

3. Esmon CT: Crosstalk between inflammation and thrombosis. Maturitas 2008, 61:122-131

4. Horrevoets AJ: Plasminogen activator inhibitor 1 (PAl-1): in vitro activities and clinical relevance. Br J Haemato/ 2004, 125:12-23.

5. Hoekstra T, Geleijnse JM, Schouten EG, Kluft C: Plasminogen activator inhibitor-type 1: its plasma determinants and relation with cardiovascular risk. Thromb Haemost 2004, 91:861-872.

6. Juhan-Vague I, Alessi MC, Mavri A, Morange PE: Plasminogen activator inhibitor-1, inflammation, obesity, insulin resistance and vascular risk. J Thromb Haemost 2003, 1:1575-1579.

7. Lyon CJ, Hsueh WA: Effect of plasminogen activator inhibitor-1 in diabetes mellitus and cardiovascular disease. Am J Med 2003, 115(Suppl 8A):62S-68S

8. Vaughan DE: Angiotensin and vascular fibrinolytic balance. Am J Hypertens 2002, 15:3S-8S.

9. Mukamal KJ, Jadhav PP, D'Agostino RB, Massaro JM, Mittleman MA, Lipinska I, Sutherland PA, Matheney T, Levy D, Wilson PW, Ellison RC, Silbershatz H, Muller JE, Tofler GH: Alcohol consumption and hemostatic factors: analysis of the Framingham Offspring cohort. Circulation 2001, 104:1367-1373.

10. Vaisanen SB, Humphries SE, Luong LA, Penttila I, Bouchard C, Rauramaa R: Regular exercise, plasminogen activator inhibitor-1 (PAI-1) activity and the $4 \mathrm{G} / 5 \mathrm{G}$ promoter polymorphism in the PAI- 1 gene. Thromb Haemost 1999, 82:1117-1120.

11. Song Y, Lynch SV, Flanagan J, Zhuo H, Tom W, Dotson RH, Baek MS, RubioMills A, Singh G, Kipnis E, Glidden D, Brown R, Garcia O, Wiener-Kronish JP: Increased plasminogen activator inhibitor-1 concentrations in bronchoalveolar lavage fluids are associated with increased mortality in a cohort of patients with Pseudomonas aeruginosa. Anesthesiology 2007, 106:252-261.

12. Ware LB, Matthay MA, Parsons PE, Thompson BT, Januzzi JL, Eisner MD: Pathogenetic and prognostic significance of altered coagulation and fibrinolysis in acute lung injury/acute respiratory distress syndrome. Crit Care Med 2007, 35:1821-1828.

13. Hermans PW, Hazelzet JA: Plasminogen activator inhibitor type 1 gene polymorphism and sepsis. Clin Infect Dis 2005, 41 (Suppl 7):S453-458.

14. Dawson S, Hamsten A, Wiman B, Henney A, Humphries S: Genetic variation at the plasminogen activator inhibitor-1 locus is associated with altered levels of plasma plasminogen activator inhibitor-1 activity. Arterioscler Thromb 1991, 11:183-190.

15. Eriksson P, Kallin B, van 't Hooft FM, Bavenholm P, Hamsten A: Allelespecific increase in basal transcription of the plasminogen-activator inhibitor 1 gene is associated with myocardial infarction. Proc Natl Acad Sci USA 1995, 92:1851-1855.

16. Sapru A, Hansen H, Ajayi T, Brown R, Garcia O, Zhuo H, Wiemels J, Matthay $\mathrm{MA}$, Wiener-Kronish J: $4 \mathrm{G} / 5 \mathrm{G}$ polymorphism of plasminogen activator inhibitor-1 gene is associated with mortality in intensive care unit patients with severe pneumonia. Anesthesiology 2009, 110:1086-1091.

17. Yende S, Angus DC, Ding J, Newman AB, Kellum JA, Li R, Ferrell RE, Zmuda J, Kritchevsky SB, Harris TB, Garcia M, Yaffe K, Wunderink RG: 4G/5G plasminogen activator inhibitor-1 polymorphisms and haplotypes are associated with pneumonia. Am J Respir Crit Care Med 2007, 176:1129-1137.

18. Haralambous E, Hibberd ML, Hermans PW, Ninis N, Nadel S, Levin M: Role of functional plasminogen-activator-inhibitor- $14 \mathrm{G} / 5 \mathrm{G}$ promoter polymorphism in susceptibility, severity, and outcome of meningococcal disease in Caucasian children. Crit Care Med 2003, 31:2788-2793.

19. Binder A, Endler G, Muller M, Mannhalter C, Zenz W: 4G4G genotype of the plasminogen activator inhibitor-1 promoter polymorphism associates with disseminated intravascular coagulation in children with systemic meningococcemia. J Thromb Haemost 2007, 5:2049-2054.

20. Garcia-Segarra G, Espinosa G, Tassies D, Oriola J, Aibar J, Bove A, Castro P, Reverter JC, Nicolas JM: Increased mortality in septic shock with the 4G/ 4G genotype of plasminogen activator inhibitor 1 in patients of white descent. Intensive Care Med 2007, 33:1354-1362.

21. Menges T, Hermans PW, Little SG, Langefeld T, Boning O, Engel J, Sluijter M, de Groot R, Hempelmann G: Plasminogen-activator-inhibitor-1 4G/
$5 \mathrm{G}$ promoter polymorphism and prognosis of severely injured patients. Lancet 2001, 357:1096-1097.

22. Westendorp RG, Hottenga JJ, Slagboom PE: Variation in plasminogenactivator-inhibitor-1 gene and risk of meningococcal septic shock. Lancet 1999, 354:561-563.

23. Dellinger RP, Carlet JM, Masur H, Gerlach H, Calandra T, Cohen J, GeaBanacloche J, Keh D, Marshall JC, Parker MM, Ramsay G, Zimmerman JL, Vincent JL, Levy MM: Surviving Sepsis Campaign guidelines for management of severe sepsis and septic shock. Crit Care Med 2004, 32:858-873.

24. Niederman MS, Mandell LA, Anzueto A, Bass JB, Broughton WA, Campbell GD, Dean N, File T, Fine MJ, Gross PA, Martinez F, Marrie TJ, Plouffe JF, Ramirez J, Sarosi GA, Torres A, Wilson R, Yu VL: Guidelines for the management of adults with community-acquired pneumonia. Diagnosis, assessment of severity, antimicrobial therapy, and prevention. Am J Respir Crit Care Med 2001, 163:1730-1754.

25. American College of Chest Physicians/Society of Critical Care Medicine Consensus Conference: definitions for sepsis and organ failure and guidelines for the use of innovative therapies in sepsis. Crit Care Med 1992, 20:864-874

26. Levy MM, Fink MP, Marshall JC, Abraham E, Angus D, Cook D, Cohen J, Opal SM, Vincent JL, Ramsay G: 2001 SCCM/ESICM/ACCP/ATS/SIS International Sepsis Definitions Conference. Crit Care Med 2003, 31:1250-1256

27. Taylor FB Jr, Toh CH, Hoots WK, Wada H, Levi M: Towards definition, clinical and laboratory criteria, and a scoring system for disseminated intravascular coagulation. Thromb Haemost 2001, 86:1327-1330.

28. Miller SA, Dykes DD, Polesky HF: A simple salting out procedure for extracting DNA from human nucleated cells. Nucleic Acids Res 1988, 16:1215.

29. Barber RC, Chang LY, Lemaire SM, Burris A, Purdue GF, Hunt JL, Arnoldo $B D$, Horton JW: Epistatic interactions are critical to gene-association studies: PAI-1 and risk for mortality after burn injury. J Burn Care Res 2008, 29:168-175

30. Hermans PW, Hibberd ML, Booy R, Daramola O, Hazelzet JA, de Groot R, Levin $M: 4 G / 5 G$ promoter polymorphism in the plasminogen-activatorinhibitor-1 gene and outcome of meningococcal disease. Meningococcal Research Group. Lancet 1999, 354:556-560.

31. Tsangaris I, Tsantes A, Bonovas S, Lignos M, Kopterides P, Gialeraki A, Rapti E, Orfanos S, Dimopoulou I, Travlou A, Armaganidis A: The impact of the PAI-1 4G/5G polymorphism on the outcome of patients with ALI/ARDS. Thromb Res 2009, 123:832-836.

32. Gentilini $D$, Vigano $P$, Castaldi $D$, Mari $D$, Busacca $M$, Vercellini $P$, Somigliana E, di Blasio AM: Plasminogen activator inhibitor-1 4G/5G polymorphism and susceptibility to endometriosis in the Italian population. Eur J Obstet Gynecol Reprod Biol 2009, 146:219-221.

33. Wang L, Bastarache JA, Ware LB: The coagulation cascade in sepsis. Curr Pharm Des 2008, 14:1860-1869.

34. Madoiwa S, Nunomiya S, Ono T, Shintani Y, Ohmori T, Mimuro J, Sakata Y: Plasminogen activator inhibitor 1 promotes a poor prognosis in sepsisinduced disseminated intravascular coagulation. Int J Hematol 2006, 84:398-405

35. Jessen KM, Lindboe SB, Petersen AL, Eugen-Olsen J, Benfield T: Common TNF-alpha, IL-1 beta, PAI-1, UPA, CD14 and TLR4 polymorphisms are not associated with disease severity or outcome from Gram negative sepsis. BMC Infect Dis 2007, 7:108.

36. Geishofer G, Binder A, Muller M, Zohrer B, Resch B, Muller W, Faber J, Finn A, Endler G, Mannhalter C, Zenz W: 4G/5G promoter polymorphism in the plasminogen-activator-inhibitor-1 gene in children with systemic meningococcaemia. Eur J Pediatr 2005, 164:486-490.

37. Kathiresan S, Gabriel SB, Yang Q, Lochner AL, Larson MG, Levy D, Tofler GH, Hirschhorn JN, O'Donnell CJ: Comprehensive survey of common genetic variation at the plasminogen activator inhibitor-1 locus and relations to circulating plasminogen activator inhibitor-1 levels. Circulation 2005, 112:1728-1735.

\section{doi: $10.1186 / \mathrm{cc} 8992$}

Cite this article as: Madách et al., 4G/5G polymorphism of PAl-1 gene is associated with multiple organ dysfunction and septic shock in pneumonia induced severe sepsis: prospective, observational, genetic study Critical Care 2010, 14:R79 